\title{
Can Man with a Movie Camera Shoot Enemy Zero? Convergence and Transcoding in Michael Nyman's Musical Scores
}

\author{
Andrea C. Valente
}

\section{I}

The experimental silent film Man with a Movie Camera (1929) directed by Dziga Vertov involved sophisticated montage techniques derived from the constructivist traditions of the Soviet avant-garde, which marked the first decades of the $20^{\text {th }}$ century. In this context, the filmmaker worked as an "engineer" who had the skills to build aesthetically "useful objects" for society (Petrić 1987, 5). In Man with a Movie Camera, Vertov created ingenious arrangements of cinematic images that resulted in a 'visual concert' film that would subsequently inspire composers to write scores to accompany it. Although Vertov left some guidelines for the musical composition for Man with a Movie Camera, they were buried in oblivion for many years in Moscow archives. It was only after the dissolution of the Soviet Union that his musical guidelines were rediscovered and became an inspirational source for film composers such as "The Alloy Orchestra" (1995) and "The Cinematic Orchestra" (2002).

Despite the fact that Vertov's guidelines were meticulously drafted to complement meanings produced by the cinematic images, not all composers have decided faithfully to follow his guidelines. Among them is the English composer Michael Nyman who in 2003 released Vertov's film with a new soundtrack licensed by the British Film Institute. In a 2009 interview, Nyman explained that he "deliberately refused to consult Vertov's musical notes on the film and the reason is that [he] 
knew [Vertov] was trained as a composer" (Nyman 2009, 161). As Nyman further explained, he had previously heard orchestras that followed Vertov's notes, and he did not want to write anything similar. Instead, he "decided to be very unfaithful to Vertov and emphatically to be very instinctive" (161), by which he meant that he would 'read' the cinematic images and relate them to his own style. His bold decision neither to follow Vertov's musical guidelines nor to write a "single note of new music for this movie" (161) may seem provocative. Nyman admits that "the music and the recordings existed in their own right prior to the film. It existed as a soundtrack to a Japanese videogame" (161). Nyman's audacious approach to the scores for Man with a Movie Camera leads to research questions that embrace interdisciplinary perspectives originating in film, media, literary, and cultural studies. My contribution aims to show that Nyman's soundtrack to Man with a Movie Camera represents a perfect example of transcoding, convergence, and adaptation. Furthermore, it argues that convergence culture is part of an intermedial process that calls for a transgenerational approach involving producer, media formats (analogue and digital), and consumers.

\section{II}

Nyman's biographer Siôn (2007) writes that the composer was born in 1944 into a middle-class Jewish family in London. He began to study music when he was eight years old, influenced by a schoolteacher who identified Nyman's musical talent at an early age and provided him with an intensive music education until his admission to the Royal Academy of Music in 1961. Later Nyman pursued his graduate studies in musicology at King's College and had his first book Experimental Music: Cage and Beyond published in 1974. By that time, he was already an experienced music reviewer and in 1977 he made his first appearance as a composer with his work for the opera In Re Don Giovanni. His first major score was written for the film The Draughtsman's Contract (1982) directed by the British filmmaker Greenaway, and the two became life-long collaborators. A decade later, Nyman achieved international recognition as a music composer with the soundtrack album to Jane Campion's film The Piano (1993).

Despite his influential body of work in the field of experimental music, $\mathrm{Ny}$ man's compositions are mostly ignored by music scholarship. His endeavours to write a film soundtrack for a video game at a time when game music was not accepted as part of popular culture have also been overlooked in media studies (Fritsch 2013, 19). In 1997, Nyman wrote the soundtrack for the Japanese video game Enemy Zero which failed to reach an international market and has remained unknown until today. Consequently, the soundtrack for Enemy Zero also fell into oblivion, a fact that Nyman later tried to overcome by adapting it as a musical score for Vertov's Man with a Movie Camera. In other words, Nyman transposed and recycled pieces of the original soundtrack into a new score for the Soviet film. The 
transposition of the soundtrack across media, that is from a video game to a DVD format to accompany a silent film, works within the paradigms of intermediality (Rajewsky 2005; Wolf 2006) and intertextuality (Barthes 1977; Kristeva 1986) that link Vertov's and Nyman's cinematic concepts. Hence my paper argues that $\mathrm{Ny}-$ man is one of the most recent successors to Dziga Vertov's legacy, and that a comparative view of these two artists becomes necessary to understand how their work converges in Man with a Movie Camera. The synergism between their works, both of which display montage techniques with regard to images and sound, becomes an important aspect of understanding their creative processes. In this context, the common features found in Vertov's and Nyman's works, such as selfborrowing, recycling, adaptation, and remediation, connect these two artists from a transgenerational perspective. For this reason, I will concentrate here on showing how they treat montage as a significant phase in their music and film composition.

\section{III}

Vertov's Man with a Movie Camera is treated here as a 'text' (Barthes 1977, 126) that invites polysemic readings. In this sense, viewers are interpreters who can translate Vertov's images according to the specificities of their time and space. According to Feldman, "those who have engaged [with Vertov] theoretically, critically, historically have constructed and reconstructed him as no more or less than those meanings that various historical moments have imposed upon him" (2007, 40). In Nyman's case, his readings of the scenes in Man with a Movie Camera become a translation of images into a musical score and thus make him a collaborator in the film.

Based on Siôn's account of Nyman's biography, this article notes some similarities between Nyman's and Vertov's creative processes. According to his biographer, Nyman's compositional approach was influenced by childhood memories of witnessing his parents using artisan methods of recycling every single fur material available. ${ }^{1}$ Siôn therefore asserts that Nyman's "musical ideas are constantly reused, reworked, recombined and recomposed" (2007, 15). This approach resembles Vertov's film "montage" in which "films beget films" (Vertov 1896$1954 / 1984,122)$ through the use of repetition, reuse, and recombination of images. Vertov's recycling techniques can be observed in some of his main films such as Man with a Movie Camera, One Sixth of the World, and Enthusiasm, in which repetition, reuse, and recombination of images become parts of a laborious process. According to Petrić, "Vertov and Svilova based their editing decisions on graphic and visual features" by gathering bits and pieces of the shots that would "reveal their full meaning within the thematic context" $(1987,27)$. Yet in Nyman's composition, repetitions of melodic motion, rhythmic patterns, and formal structures

1 Nyman's parents worked in the fur trade, cutting and sewing furs to make coats (Siôn 2007, 15). 
characterize a 'minimalist' style that he developed while studying Cage's experimental music. In both Vertov's and Nyman's creative processes, the practice of recycling an image or a rhythmic pattern and then transposing it to another medium, that is to a new film or to another soundtrack, becomes a clear example of intermediality. While transposing can simply be seen as a shift from one medium into another, intermediality works on the level of meaning-making by which distinct cultures, values, and aesthetics are created across media.

Despite advocating the use of musical quotation in his scores, Nyman observes that "one of the problems with recycling other composers' music is that it has to be an enrichment, not a diminishing" (transcribed from Nyman 1999). In other words, adding the voices of others to one's text becomes an example of inclusion and integration that allows dialogism. Moreover, Vertov and Nyman share similar attitudes towards experimental art (image and sound), offering the audience new aesthetic experiences of seeing and listening. In their works, they provide images and sound that overlap through repetition and are multi-layered, which creates a multi-sensory experience.

Apart from similarities in the montage methods, these two artists seem to converge on a political level. For example, Vertov's anti-bourgeois attitude to cinema is reflected in his manifesto against filmmakers who made use of theatrical and literary artifices to alienate their audience from reality. For this reason, he decided to make films that show 'life as it is,' or better, "life caught unawares" (Petrić 1987, 4) by casting real people and shooting in real places. Similarly, Nyman's decision for a minimalist music style leads him to experimental techniques that keep him away from the classical music tradition. Instead, he chooses an approach that emphasizes repetition of structures, known as 'serialism,' which is usually associated with popular music. Moreover, Nyman remarks that experimental music is concerned with the "process of generating action" rather than the prescription of a "defined time-object" $(1981,3)$, that is being in conformity with the mainstream. Such a position also holds true for Vertov's documentary films since they focus on the process of editing rather than on the product, as drama films usually do with their 'attractions' to alienate the viewer. The notion of generating action by means of experimental artwork matches the revolutionary thoughts defended in Vertov's 1922 "Manifesto"; however, it did not disavow the realistic illusion Vertov himself created with his Kino-eye.

\section{IV}

Enemy Zero is a video game released in 1997 for Sega Saturn consoles, developed by the electronic company WARP, and directed by the Japanese game designer Kenji Eno. Enemy Zero was influenced by the bestselling film Alien (1979). It is about Laura, an android, who is the only survivor in a spacecraft that has been attacked by invisible enemies. In order to survive, Laura can only rely on her hearing skills 
to defend herself from the invisible aliens. When Laura hears certain beeps or tones, she knows that the enemy is close. For example, when the tone is higher, the enemy is ahead of her; when it is lower, it is behind her; and when it is medium, it is either to her right or left. The objective of the game is to have Laura rescue the spaceship, fight against the enemy, and return to Earth. The aural features add information to the images and become essential elements for playing the game successfully. In one of his interviews, Eno explained that the sound feature makes the film challenging and difficult for the player, who needs to rely not only on the usual visual skills but also on audio skills to play the game. Eno believes that the level of difficulty the player faces explains the game's low popularity. Being one of Nyman's fans, Eno insisted on having the composer collaborate on the score for Enemy Zero. He explained to his fans in an online interview: "I felt he's the best musician for what I was looking for in Enemy Zero." $2 \mathrm{He}$ also stated that it was not an easy task to convince Nyman to write the score for the video game. In the end, they agreed to embark on a joint venture, in which Nyman ended up creating the soundtrack for Enemy Zero based on Eno's storyboard and suggestions.

Nyman divided the soundtrack into fourteen pieces that accompany the narrative sequences with titles summarizing the main idea of each track. For example, in scenes that focus on Laura, Nyman wrote specific scores to accompany her movements, actions, and feelings, such as "Laura's Theme" and "Laura's Dream." They are compositions for the piano with melodic movements in adagio. Other tracks, such as "Aspects of Love," "Love Theme," "Lamentation," and "The Last Movement," follow similar musical arrangements to accompany scenes featuring flashback, memory, romance, and melancholy. For moderato tempo with motion, Nyman wrote the track "Confusion" that sets the pace for undertaking an adventure. To create suspense and excitement when the enemy is around, he composed "Digital Tragedy," "Digital Complex," "Invisible Enemy," and "Malfunction." For the track "Agony," Nyman arranged a hybrid score, in which he used a combination of a soprano singer and orchestra, making the whole piece develop into a crescendo. This track accompanies the scenes in which Laura finds out that the enemy has killed the whole crew and she has to escape immediately. The fast tempo to convey speed and action is used to represent Laura's confrontation with the enemy, which is followed by the tracks "Enemy Zero" and "Battle." Nyman's soundtrack enhances the player's aesthetic experience and emotional response as each track takes the player to the next level in the game. In this manner, the story and the musical narratives resemble Freytag's pyramid model of storytelling for classical drama (i.e. exposition, introduction of a conflict, rising action, climax, falling action, and resolution; see Herman, Jahn, and Ryan 2005, 189). For example, the tempo in each track signals the game's narrative sequence, which is usually marked

2 As Eno suddenly passed away in 2013, the interview from the year 2008 has been removed from the internet. Extracts of the interview, however, were reproduced in Electronic Gaming Monthly 232 (2008). 
by either a progressively rising pitch to indicate acceleration or a decreasing pitch to indicate deceleration. If it is a progressive tempo, it signals the reaching of the climax in the story; if it is a decreasing one, it signals the resolution. Hence, Nyman's track sequences closely follow the structure of Freytag's dramatic model: the game starts with a gentle piano tune ("Laura's Theme") and progressively accelerates towards the scenes of suspense, horror, death, and invisible attacks ("Digital Complex," "Enemy Zero," and "Battle"). The climax is followed by the track "Agony," and the falling action is accompanied by "The Last Movement." The resolution of the game's story is indicated by the track "Laura's Theme."

Nowadays, media convergence allows an individual to watch Enemy Zero as a 'game-film' on YouTube, thus transforming the role of the player into that of the viewer. In the film version, the viewer can watch a continuous interaction between images and music, which leads to a 'third composition.' According to Vertov, the third composition is "neither in the sound nor in the image but [...] exists only in the continual interaction of sound recording and image" (1896-1954/1984, 243). From a poststructuralist perspective, the interaction between images and sounds works on the level of two independent elements that are juxtaposed to each other and maintain separate identities. In this regard, the viewer is left with at least the following options: either to turn the volume down and view the film without sound, or to minimize the YouTube window and listen to the soundtrack without the images. The latter option relies on the viewers' aural skills and on their mental images of the same or another film. In this case, both images and sound pieces become free-floating entities that can be transcoded into other media. Hence, $\mathrm{Ny}$ man's soundtrack for the video game - seen here as the 'source' - is adapted into a DVD format to accompany Vertov's silent film Man with a Movie Camera.

In this regard, Michael Nyman's adaptation for Vertov's film soundtrack challenges Adorno and Eisler's modernist ideas as presented in their book Composing for the Films (1947). Their composition guidelines, such as "insertion of the music should be planned along with the writing of the script" (Adorno and Eisler $1947 / 2007,5)$ and "the task of the composer is to compose music that fits precisely into the given picture" (47), are based on Eisler's experience in writing scores for Hollywood feature films during the Second World War. In that period, experimental endeavours lacked support and technological assistance for musical scores was in its infancy. Over three decades later, taking advantage of technology and adhering to postmodernist views, Nyman converges old and new media in his work. With the advent of software to enhance musical composition, the term 'database' moves beyond the computer and reaches art forms such as film and music, which become available during montage in order to assist with image and sound cataloguing and storing in diverse formats. The media scholar Lev Manovich opens up discussions on databases, mentioning that pieces of image or sound are seen as independent media elements that can be "assembled into largerscale objects but continue to maintain their separate identities" (2001, 30). Moreover, editing into different formats becomes only possible due to 'transcoding,' a 
term that Linda Hutcheon borrows from Manovich and incorporates in her study on adaptation (2013). According to Manovich, transcoding is a way "to translate [something] into another format" $(2001,47)$ or in Hutcheon's words, it is "a shift of medium, or genre or a change of frame and therefore context" (2013, 7). From this perspective, Vertov's film Man with a Movie Camera and Nyman's soundtrack for Enemy Zero seem appropriate examples that support the transcoding principle. For instance, Vertov's film was originally only available in reel format and has only recently been digitally transcoded into DVD format, which offers the viewer the choice to watch the film in a variety of ways that change the audience's habits of watching films. Moreover, Nyman's soundtrack for the video game Enemy Zero becomes a 'platform' that he can transcode either into a musical score for Man with a Movie Camera in a digital version to accompany the film DVD or into a live concert played by Nyman's band in theatres. These two cases are paradigmatic examples of convergence culture defined in Jenkins's work as the "flow of content across multiple media platforms" $(2008,2)$.

Based on these examples, this paper asserts that transcoding allows more fluidity not only in the contents and/or database but also in the narrative. In contrast to the video game Enemy Zero, whose soundtrack follows a story sequence, the music in Man with a Movie Camera is remixed, relocated, and re-contextualized in order to "create different interpretations," as Hutcheon suggests in her theory of adaptation (2013 , 8). Taking into account Vertov's introductory intertitle to Man with a Movie Camera, which announces that this is a "film without narrative," this paper similarly argues that Nyman's soundtrack to the silent film follows a Vertovian principle and is a soundtrack without narrative. In this sense, transcoding allows the remixed tracks to interact with different images, which creates a new text with different meanings for Man with a Movie Camera.

\section{V}

At first sight, Nyman's explanation for using a recycled composition for Man with a Movie Camera may sound disappointing to his fans. Nyman's straightforward comments on self-plagiarism and self-stealing, which destroy the 'aura' of his composition for the silent film, are bluntly mentioned in one of his interviews: "I'm not a great inventor from scratch. What I do is to use, steal, acquire, reproduce or recycle music from other musicians" (Nyman 2002).

To gain a better understanding of Nyman's position and intention, this paper takes into account some ideas from New Media theory concerning databases, conversions of data files, compression of file formats, and data transformation. $\mathrm{Ny}$ man uses the Enemy Zero soundtrack as a platform to depart from. Contrary to the video game, in which the soundtrack follows a narrative sequence as illustrated above with Freytag's pyramid, the remixed tracks in Man with a Movie Camera are non-linear, superimposed, and even reduced. Nyman divides the new soundtrack 
into nine titles that are recycled and remastered. To illustrate this, the following table (table 1) shows how Nyman's 'original' for Enemy Zero corresponds to the titles from the film Man with a Movie Camera released in DVD format in 2003.

\begin{tabular}{|l|l|}
\hline $\begin{array}{l}\text { TITLES from Man with } \\
\text { a Movie Camera }\end{array}$ & TRACKS from Enemy Zero \\
\hline Intro & $\begin{array}{l}\text { Agony (1:38) } \\
\text { Battle (2:03) }\end{array}$ \\
\hline Awakening & $\begin{array}{l}\text { Laura's Theme (4:28) } \\
\text { Digital Tragedy (8:21) }\end{array}$ \\
\hline Locomotion & $\begin{array}{l}\text { Invisible Enemy (13:08) } \\
\text { Lamentation (17:00) }\end{array}$ \\
\hline Assemblage & Enemy Zero (20:21) \\
\hline Life Goes On & $\begin{array}{l}\text { Aspects of Love/Love Theme (24:54) } \\
\text { Confusion (28:51) } \\
\text { Lamentation (33:05) }\end{array}$ \\
\hline Manual Labour & $\begin{array}{l}\text { Confusion (36:33) } \\
\text { Invisible Enemy (37:24) } \\
\text { Malfunction (39:32) }\end{array}$ \\
\hline Recreation & $\begin{array}{l}\text { Aspects of Love (43:48) } \\
\text { Laura's Dream/Laura's Theme (47:26) } \\
\text { Confusion (51:26) }\end{array}$ \\
\hline Relaxation & Battle (54:47) \\
\hline Cinematic I & $\begin{array}{l}\text { Agony (59:34) } \\
\text { Invisible Enemy (1:00:34) } \\
\text { Enemy Zero (1:04:49) }\end{array}$ \\
\hline
\end{tabular}

Table 1: Titles and tracks

The table is divided into nine sections, each of which is given a title to summarize a narrative sequence. Each title recycled for the film corresponds to at least one track from Enemy Zero. Moreover, some tracks are remastered and played again under another title. The table illustrates the principles of 'transcoding' and 'convergence' and shows how tracks interact with different images and how new meanings emerge that bring uniqueness to the scenes. In addition, Nyman's recycling of the Enemy Zero soundtrack for the DVD version of Man with a Movie Camera produces a new text within a new context. In other words, it includes a process of "recontextualization" (Bauman and Briggs 1990, 75) that suggests new formal and functional implications for both Vertov's film and Nyman's soundtrack. The 'death' of the original soundtrack with its corresponding narrative and dramatic elements resurrects the Soviet film as a visual symphony of a city film that unfolds the everyday life of its city dwellers before the camera, in Vertov's words a "naked eye [...] of visual chaos of fleeting life" (1896-1954/1984, 285). Accordingly, the challenge for Nyman is to have a soundtrack that can "keep pace with life's fleeting phenomena" 
(Vertov 1896-1954/1984, 287). It seems that Nyman's minimalist approach produces a soundtrack able to keep pace with the images unfolding on the screen. In other words, the minimalist musical techniques Nyman uses, i.e. repetition, "contrapuntal layering," and "chugging pulse" (Schwartz 1996, 200), converge with Vertov's experimental film.

To express movement in Man with a Movie Camera, Vertov uses film techniques that suggest convulsion, ecstasy, and a frenzy of images, such as freeze frames, slow motion, fast motion, reverse motion, and split screens. Hence, to accompany the pace of the frenetic images, it is necessary to have a soundtrack that captures the Zeitgeist of the film. To illustrate this, the title "Locomotion" represents the pace of the city expressed through shots of public transportation (e.g. street cars, buses) and pedestrians in a rush to start a working day routine in the metropolis. The accompanying track is "Invisible Enemy," which was originally played in Enemy Zero when Laura tries to escape from the enemy; metaphorically, it expresses a 'battle' faced by the ordinary city workers. Still in the same sequence, there is the track "Lamentation" that originally accompanied Laura as she finds out that "Enemy Zero' has killed the crew. Yet, in Man with a Movie Camera, "Lamentation" is translated into a soothing melody to suggest the workers' dull everyday routine, such as getting ready for work, opening a store, delivering early mail, and directing traffic. Although the next scenes still deal with the hustle and bustle of a big city, the slow tempo in the following tracks creates the illusion that life is becoming easier for the workers. The alternation of fast and slow tempos with ascending and descending notes within the scenes becomes a pattern in the soundtrack throughout the film and accompanies the vicissitudes of life (i.e. birth, marriage, divorce, death) as witnessed by the camera eye.

Along with representations of acceleration in Man with a Movie Camera and its soundtrack, notions of space are also explored through images and sound. The original soundtrack composed for Enemy Zero accompanies indoor scenes in a spacecraft where silence, metallic coldness, and emptiness set the tone for the story. Yet the space in Man with a Movie Camera is mostly explored through outdoor shots of an emergent metropolis in the Soviet region in the late 1920s. To provide a perfect match, Nyman's soundtrack needs to take into account the outdoor features in Vertov's film. He is challenged to match the remastered tracks with images and scenes that trigger aural and visual associations, as in the sequences of the traffic controller, the honking of the cars, and the performance of the spoons and bottles (Petrić 1987, 177). These examples imply an intra-diegetic sound naturally emanating from the images, which Nyman's soundtrack has to take up to provide an aural suggestion of loud and intense noise and sound.

Instead of provoking auditory sensations that compete with the images, $\mathrm{Ny}$ man's remixed soundtrack creates a new aesthetics by adding another layer to the images. However, one might suspect that Vertov's reaction to Nyman's compositional montage would be far from positive. Tsivian mentions that Vertov instructed the orchestra "to keep silent while the scene of the projectionist was shown" 
$(1994,120)$ during the Prologue sequence (i.e. Intro), with only a ticking sound of the film projector to be heard. However, in Nyman's remixed work, the sequence uses the track "Battle" (2:03) as accompaniment, which offers the viewer the opposite aesthetic experience: instead of a silence that lets the images speak for themselves, a loud noise eclipses the images.

Analyzing Man with a Movie Camera through a New Media lens, Manovich identifies three layers in the structure of the film $(2001,241)$. The first layer concerns the story of a cameraman who shoots the scenes for the film. The second one refers to the audience watching the shots of the finished film in a movie theatre. The third layer is the film itself, which contains the footage recorded in the cities of Moscow, Kiev, and Riga, and which Manovich considers as the text itself (i.e. the raw material). In this context, the first two layers are regarded as 'metatext' (i.e. a language about another language). Since Manovich does not mention the sound material, this paper restores the soundtrack as a medium that occupies a fourth layer, functioning as a metatext as well: here, the musical text is 'plugged in' to augment the visual text. As a consequence, the fourth layer refers to the remixed soundtrack that functions as an 'add-on' to the images. This alternative interpretation challenges the traditionally divided role assigned to film music: that of diegesis (i.e. music as part of the story) and that of non-diegesis (i.e. background music) in the cinematic narration. Nyman's composition is placed neither inside nor outside the narrative. Instead, it overlays the cinematic text as an additional layer, one that can bring ambiguities and tensions to the images. This may explain some of the criticism that Nyman's remixed soundtrack has received in online film reviews.

\section{VI}

As Nyman uses extensive (self-)borrowing in his compositions, his work can become an easy target for criticism that considers originality in the sense of Romantic genius as the highest artistic achievement. However, he defends himself against accusations of being unoriginal:

while I would not deny the accusation of borrowing, only about $20 \%$ of my music is based upon reworked material from other composers. I would also strongly contend that I always transform what I take into something totally fresh and musically challenging, in just the same way that Stravinsky might have done. (qtd. in Siôn 2007, 2)

Nyman's affiliation with postmodernist approaches to contemporary art should not be taken as a period-specific attitude. Vertov himself also used montage techniques that included recycling and reusing of film material as part of a collage of his own borrowings from previous shots. Hence it may not be fair to criticize 'borrowing' as a technique that signals one's lack of originality solely on the grounds of traditional perspectives influenced by Romantic aesthetics. As convergence of old 
media (e.g. photography, cinema, and TV) and new media (e.g. computer and internet) becomes more frequent, the notion of originality needs to be reconceptualized. We cannot deny that the creation of databases in computational studies has come to assist artists in cataloguing and storing moving images and sounds as 'independent texts' that become available for reusing in other formats. Siôn explains that Nyman's tendency to borrow musical quotations has been influenced by the malleability allowed in the Baroque style. Siôn emphasizes that "endless adaptability and versatility of musical gestures, phrases, turns and figures belonging to the Baroque and Classical styles" $(2007,6)$ have greatly contributed to Nyman's style. Although it is possible that Baroque style has influenced Nyman's work, especially with him being a musicologist himself, his remixed soundtrack as analyzed in this article shows that Vertov's montage approach has also served Nyman as an inspirational source that works at the level of intermediality.

Vertov's definition of montage as "organizing film fragments (shots) into a film-object as if one is writing something cinematic with the recorded shots" (1896-1954/1984, 88) resonates with Nyman's approach of re-arranging musical elements (e.g. chord structures) from previous scores into a new composition. This may evoke associations between the 'original' object and the 'recycled' one. Moreover, the creation of an inventory of montage by gathering all "documentary data directly and indirectly" (89) and the "continuous shifting of all the pieces until all are placed in a rhythmical order such that all links of meaning coincide with visual linkage" (90) can be expanded to sound montage. Hence, the process of editing involves some sort of organic and technological work by the artist, whether filmmaker or music composer, which goes beyond simply putting pieces together. Here montage involves 'labour,' a physical effort that goes by the metaphor of a bricoleur, a term used by Lévi-Strauss and further elaborated by Genette to refer to the individual who "creates a structure out of a previous structure by rearranging elements which are already arranged within the objects of his or her study" (Allen 2011, 96).

In conclusion, this article acknowledges Nyman as an artist representing Vertov's work, not in the sense of being a follower of Vertov's musical guidelines but in his approach to capturing the essence of Vertov's film montage technique as an 'unfaithful' translator of Vertov's musical guidelines for Man with a Movie Camera. Furthermore, it illustrates that convergence and transcoding principles can be understood as intermedial processes that transcend the boundaries between old and new media. 


\section{Works Cited}

Adorno, Theodor W., and Hanns Eisler. Composing for the Films. 1947. London and New York: Continuum, 2007.

Allen, Graham. Intertextuality. 2000. 2nd ed. London and New York: Routledge, 2011.

Barthes, Roland. "From Work to Text." Image, Music, Text. Trans. Stephen Heath. New York: Hill and Wang, 1977. 155-164.

Bauman, Richard, and Charles L. Briggs. "Poetics and Performance as Critical Perspectives on Language and Social Life." Annual Review of Anthropology 19 (1990): 59-88.

Enemy Zero. Dir. Kenji Eno. Tokyo, Japan: Developed by WARP Inc., 1996. CD.

Feldman, Seth. "Vertov after Manovich." Canadian Journal of Film Studies 16.1 (2007): 39-50.

Fritsch, Melanie. "History of Video Game Music." Music and Game: Perspectives on a Popular Alliance. Ed. Peter Moormann. Wiesbaden: Springer VS, 2013. 11-40.

Herman, David, Manfred Jahn, and Marie-Laure Ryan, eds. Routledge Encyclopedia of Narrative Theory. London and New York: Routledge, 2005.

Hutcheon, Linda. A Theory of Adaptation. 2006. 2nd ed. London and New York: Routledge, 2013.

Jenkins, Henry. Convergence Culture: Where Old and New Media Collide. 2006. New York: New York UP, 2008.

Kristeva, Julia. "Word, Dialogue and Novel." The Kristeva Reader. Ed. Toril Moi. New York: Columbia UP, 1986. 34-61.

Manovich, Lev. The Language of New Media. Cambridge, MA: MIT Press, 2001.

Nyman, Michael. Experimental Music: Cage and Beyond. 1974. New York: Schirmer Books, 1981.

---. "BBC Radio 4 - Desert Island Discs - Castaway: Michael Nyman." 19 December 1999. Podcast. Web. 15 March 2014.

---. "He's Got that Thinking Feeling." Interview by Peter Conrad. The Observer. 12 May 2002. Web. 23 September 2013.

---. "The Power of Musical Montage: Michael Nyman's Soundtrack for Vertov's Man with a Movie Camera." Scroope 19 (2009): 160-163.

Petrić, Vlada. Constructivism in Film. The Man with the Movie Camera: A Cinematic Analysis. Cambridge: Cambridge UP, 1987. 
Rajewsky, Irina. "Intermediality, Intertextuality, and Remediation: A Literary Perspective on Intermediality." Intermédialités 6 (2005): 43-64.

Schwarz, Robert. Minimalists. London: Phaidon Press, 1996.

Siôn, Pwyll. The Music of Michael Nyman: Texts, Contexts and Intertexts. Aldershot, Hants: Ashgate, 2007.

Tsivian, Yuri. Early Cinema in Russia and Its Cultural Reception. 1991. Trans. Richard Taylor. London and New York: Routledge, 1994.

Vertov, Dziga, dir., and Michael Nyman. Man with a Movie Camera. 1929. London: BFI, 2003. DVD.

Vertov, Dziga. Kino-Eye: The Writings of Driga Vertov. 1896-1954. Ed. and introd. Annette Michelson. Trans. Kevin O’Brien. Berkeley: U of California P, 1984.

Wolf, Werner. "Frames, Framings and Framing Borders in Literature and Other Media." Framing Borders in Literature and Other Media. Ed. Walter Bernhart and Werner Wolf. Amsterdam and New York: Rodopi, 2006. 1-42. 